\title{
Article
}

\section{Food Logistics 4.0: Opportunities and Challenges}

\author{
Sandeep Jagtap ${ }^{1, *(\mathbb{D})}$, Farah Bader ${ }^{2}$, Guillermo Garcia-Garcia ${ }^{3} \mathbb{D}$, Hana Trollman ${ }^{2} \mathbb{D}$, Tobi Fadiji 4 (D) \\ and Konstantinos Salonitis ${ }^{1}$ (D)
}

1 School of Aerospace, Transport \& Manufacturing, Cranfield University, Cranfield MK43 0AL, UK; k.salonitis@cranfield.ac.uk

2 School of Mechanical, Electrical \& Manufacturing Engineering, Loughborough University, Loughborough LE11 3TU, UK; f.n.k.bader@lboro.ac.uk (F.B.); h.trollman2@lboro.ac.uk (H.T.)

3 Department of Chemical \& Biological Engineering, The University of Sheffield, Sheffield S1 3JD, UK; g.garcia-garcia@sheffield.ac.uk

4 Africa Institute for Postharvest Technology, South African Research Chair in Postharvest Technology, Postharvest Technology Research Laboratory, Faculty of AgriSciences, Stellenbosch University, Stellenbosch 7602, South Africa; fadiji@sun.ac.za

* Correspondence: s.z.jagtap@cranfield.ac.uk

Citation: Jagtap, S.; Bader, F.;

Garcia-Garcia, G.; Trollman, H.; Fadiji,

T.; Salonitis, K. Food Logistics 4.0:

Opportunities and Challenges.

Logistics 2021, 5, 2. https://doi.org/

10.3390/logistics5010002

Received: 23 November 2020

Accepted: 22 December 2020

Published: 30 December 2020

Publisher's Note: MDPI stays neutral with regard to jurisdictional clai$\mathrm{ms}$ in published maps and institutional affiliations.

Copyright: $\odot 2020$ by the authors. Licensee MDPI, Basel, Switzerland. This article is an open access article distributed under the terms and conditions of the Creative Commons Attribution (CC BY) license (https:// creativecommons.org/licenses/by/ $4.0 /)$.

\begin{abstract}
Food Logistics 4.0 is a term derived from Industry 4.0 focusing on all the aspects of food logistics management based on cyber-physical systems. It states that real-time information and the interconnectivity of things, supplemented with novel technologies will revolutionise and improve the way food logistics is carried out. It has tremendous potential in terms of bringing transparency, swift delivery of food at reduced cost, flexibility, and capability to deliver the right quality product at the right place and at the right time. This paper discusses the vital technologies within Food Logistics 4.0 and the opportunities and challenges in this regard. It focuses primarily on food logistics, including resource planning, warehouse management, transportation management, predictive maintenance, and data security. Internet of Things, Blockchain, Robotics and Automation and artificial intelligence are some of the technologies discussed.
\end{abstract}

Keywords: additive manufacturing (3D printing); artificial intelligence; augmented reality; big data; Blockchain; cybersecurity; food logistics; Industry 4.0; internet of things; robotics and automation

\section{Introduction}

Industry 4.0 is a term derived from the German word Industrie 4.0 which originated in 2011 at the Hannover trade fair [1]. It was a German government high-tech strategy to promote digitalisation/computerisation of manufacturing and increase automation compared to the third industrial revolution. Industry 4.0 was initially based on nine pillars [2] which are as follows: Robotics and automation, Big data, Simulation, System integration, Internet of Things, Cybersecurity, the Cloud, Additive manufacturing (3D printing) and Augmented reality. The main objective of Industry 4.0 technologies is to make manufacturing more cost-effective, to provide agility and flexibility with high-speed manufacturing and enhanced quality.

Food logistics is a vital element of the food supply chain [3]. It is an important aspect of fulfilling consumer demands by providing the right product and quantity at low-cost and on-time delivery with minimum or no food waste since the majority of food products have a very short shelf-life. It includes both cold and ambient logistics involving precise planning, execution, and efficient monitoring to effectively manage the movement of food products from farm to fork with minimum resources and wastage but at the same time satisfying consumer needs. In the UK, $89 \%$ of all goods are transported by road and this percentage increases to $98 \%$ when it comes to transportation of agri-food products [4]. Food logistics has always been service-driven with significantly high competition and low-margin business but at the same time reacting to inconsistent consumer demands. 
Food logistics businesses have embraced information technology in their daily operations to manage both road and food safety compliances, road conditions including congestions, service level (on-time in-full delivery), and to improve environmental performance. Furthermore, the food logistics market has become more saturated over the last couple of decades and new customer demands are adding more pressure and making more complicated systems. Other contributing factors such as shelf-life, globalisation, demographic trends, fluctuating customer demand for customised food products (e.g., gluten-free, low sugar and salt, low calorie, etc.), and ethical sustainable standards are also adding to the pressure. However, more needs to be done in order to modernise food logistics by developing innovative solutions for improving the overall sustainability i.e., environmental, social, and economic performance.

Although food logistics have become more efficient over the years, Industry 4.0 technologies are only recently beginning to be adopted. With this current inclination towards Industry 4.0 technologies, new approaches to food logistics are required to reduce logistics costs and carbon emissions in order to improve overall sustainability. Hence, it has become crucial to address these issues and to increase food sector awareness and understanding of the importance of Industry 4.0 while recognising the opportunities and challenges of Food Logistics 4.0. Therefore, this paper focuses on the role of Industry 4.0 technologies in the context of food logistics termed 'Food Logistics 4.0'. In addition to discussing the nine technologies stated earlier, we also consider Blockchain technologies and Artificial Intelligence in this paper. Finally, we conclude the paper with comments on the impact of Food Logistics 4.0.

\section{Robotics and Automation}

Robotics and automation are two components of the first pillar of Industry 4.0 [5]. While robotics refers to the process of designing and using a robot to carry out specific tasks, automation is the use of other forms of automatic mechanised technology. The use of robotics and automation in any business is driven by the company's desire to reduce costs, increase production quantity and operation speed. Processes performed by robotics and automation also provide higher efficiency and an improved working environment [6]. Robotics, considered a form of automation, provides businesses with production flexibility, which is specifically important when a sudden change to meet consumer demands is required [7].

Robots, in their various configurations, can be programmed to manipulate objects and carry out tasks continuously and consistently. The implementation of robotics in food logistics spans all industry-wide functions. Initially, robots were mostly used in packaging and palletising, but over the past couple of years, other applications have increased [8]. Integrating robotics and automation into food logistics operations allows for end-to-end tracking and traceability throughout the supply chain. This is particularly important for food products that are perishable and with strict handling conditions requirements [9]. Optimisation of goods handling and transport is the greatest benefit of robotics application in logistics. Robotic applications offer optimised flow and tracking of material throughout the logistics process. Robotics are often combined with sensors and imaging technologies [7].

The introduction of automation and robotics enables companies to remove employees from hazardous working environments; typically, in which human labour must load and unload heavy goods causing physical strain or operate forklifts in uncomfortable settings. Automating such processes may result in the redistribution of employees and better work settings [7]. Pal and Kant [9] expect the greater implementation of automation in logistics for material handling upon arrival, primary processing such as sorting, quality monitoring as well as packaging and palletising. Typically, the goods being handled are standardised and flow along a single pre-defined process. Higher levels of automation, i.e., robotics, are required for the handling of non-standardised goods [7].

Automating operations mainly increases productivity by decreasing the time required to carry out tasks, thus increasing output and profit. Product quality is also increased 
by the precision associated with automation, therefore reducing defects, meeting production requirements, creating less waste and more profit. The more productive a system, the greater the market competitiveness. Moreover, the implementation of automation and robotics within a company labels them as innovative, increasing competitive advantage [7].

In terms of warehouse logistics, simple basic automation can aid immensely in the movements of products; examples include the use of automated guided vehicles (AGV). The use of AGV allows for increased productivity as well as decreased labour and operating costs. Perhaps the greatest benefit of using AGV to transport products is the flexibility in controlling their path, meaning the facility may be rearranged as required easily [10]. Robotics can also be used in such settings, in which swarm robots move around products on mounted railings [11]. Moreover, robotics can be seen in transport, sorting, packaging and delivery of products [10]. Proximity sensors and warning systems are attached to these mobile robots to ensure the safety of the environment in which they operate, which may also include the presence of human labour. Drones can also be used in the monitoring and management of inventory within production facility warehouses.

As more companies adapt to Industry 4.0, automation will become more widespread and affect the entirety of the supply chain, spanning all of the food industry's sectors. Despite the promising benefits of automation and robotics, many companies hesitate to adopt them in logistics, mostly due to the lack of understanding of the technology, and their concerns regarding the cost of investment and maintenance of such systems [11,12]. Therefore, there is a need to disseminate information on the benefits of automation and robotics within the food logistics sector.

\section{Big Data}

Big data is data that is diverse (variety), generated in large amounts (volume) and at a very high speed (velocity), usually known as the three vs. [13]. However, many sectors including food supply chain partners are using this technology to extract value [14] from this varied, voluminous, and high-speed (velocity) data, which are also represented by 4 Vs (Variety, Volume, Velocity and Value).

The developments in big data could deliver numerous benefits to the food logistics sector. With regards to food logistics, a large amount of data is generated since a huge number of food products are handled. These data can be related to their source of origin, movement in the chain, dimensional parameters (size, weight), quality (appearance), freshness, environmental conditions (temperature, humidity, microbial activity, etc.) and location [15]. These data are generated multiple times during a day and are continuously monitored. There is great potential to use these data to improve the operational efficiency, customer service level and experience as well as creating new services and business models. For example, big data can be used to optimise truck delivery routes [16,17] by processing data in order to find or alter the delivery routes based on traffic congestions or road accidents thus preventing food waste caused by delayed transportation due to traffic congestion. Traditional planning and scheduling approaches are more dependent on prediction-based historical data or staff to make decisions based on their past experiences, or rely on supply chain partners to feed accurate data often leading to inefficiencies. Big data can greatly increase the reliability of planning and scheduling by tallying up the demand, capacity and resources available in real time, supporting stakeholders with better decision-making. Big data analytics has been quite beneficial in gaining customer insights related to demands and feedback on service level performance. Big data analytics allows the processing of voluminous data from multiple sources to create meaningful insight not only on customer satisfaction but operational performance, forecasting, inventory and transportation management. Big data could also address issues such as estimating the delivery times and capacity availability including planning in real time. Big data is not only a vast source of useful information but can also be used to develop innovative solutions and services to generate additional revenues. 
Although Big data has many benefits, it also has its own challenges such as storage of data, searching and sharing of data, analysing the data and visualising it. However, Big data could add to the financial pressures of food logistics partners as monitoring, processing and storage of data would need high-end hardware and software, and as the amount of data increase daily, the system would need continuous upgrading. Other issues with big data within food logistics include data inconsistencies, scalability problems as well as data insecurity, and there is no one-stop solution to cater to multimodal data sources. Data insecurity can reveal crucial information regarding intellectual property (recipes, business secrets and services), business practices, financial status, and personal information. The vast amount of data generated consists of both valuable and confidential information which could be a reason for cyberattacks. Although personal data may be useful to provide targeted or relevant services, there is also the danger of preferential or discriminative practices. For example, supermarket chains operating multiple stores across the country could use big data to adopt a varied pricing strategy for similar products based on customer earnings, employment rate and criminality within a locality where they operate.

\section{Simulation}

Simulation is a key building block of Industry 4.0 technologies and often used for planning and developing exploratory models for efficient decision-making as well as to design operations of complex production systems. It also supports supply chain partners in assessing the risks and costs involved in their operations, system implementation barriers and impact on operational performance [18]. With more food supply chain partners under tremendous pressure to transform and to achieve efficiency and performance targets, new systems and processes certainly include numerous unidentified activities that can be hard to predict but at the same time costly and time-consuming to make right the first time. Traditionally, static modelling has aided with certain aspects; however, with the increased demand on supply chain partners to transform, predictive digital twin proposes to deliver dynamic and smart ways of modelling all phases of the food supply chain processes, creating higher business value and exceptional insight. Digital twin allows supply chain partners to model their processes within a simulated setting to enable testing and trialling of new options of working. Digital twin imitates real-life settings such as production lines and floor which can be continuously assessed to identify any opportunities for further improvement. Food supply chain partners are able to know the future impact and outcome of each situation without experiencing any risks in terms of costs and brand reputation.

Similarly, in food manufacturing and logistics systems, modelling and simulation allows the testing and validation of products, processes, systems design and to predict system performance. It also supports the decision-making process, education and training sessions, leading to a reduction in costs [19]. Furthermore, simulation can be used for forecasting, evidencing, justifying, recommending, and for practical direction. For example, Mars, the United States (US)-based confectionery, sought to increase efficiencies throughout its six sites in the US without compromising the quality of products manufactured [20]. However, each site faced complex internal supply chain issues generated by varied chocolate-producing capabilities, several chocolate varieties and inconsistent product mix and consumer demands. Initial research showed that for addressing these issues, more sophisticated modelling capabilities are required, therefore a simulation model predicting supply chain performance based on the above variables was created. This provided Mars with insight into current and intended future operations based on simulation. The result was risk recognition and capitalisation on opportunities to achieve cost savings and performance-related improvements. Hoffa-Dabrowska and Grzybowska [21] demonstrated the use of simulation modelling in consolidating the transport order to improve the sustainability of the supply chain. This resulted in reducing the number of trucks on the road leading to lesser carbon emissions, congestion, and accidents. Therefore, simulation 
models can support scheduling deliveries, designing storage locations, defining of expiry or usage rates, transport capacities and lead times, automated systems, and process times.

Simulation has its own challenges, such as physically testing all the scenarios in the food supply chain may not be possible and also the simulation software can be highly complex which may require significant learning and training for users. Investment in technology and training support from the simulation provider are required. Supply chain partners may need to assign suitable resources to train existing staff or hire new staff which may be a significant cost in terms of finding, training, and paying. Other challenges associated with simulation tools are that they provide limited interoperability between different supply chain partners. As some of the food supply chains are very complex, this adds to the complexity and would require a high-performance simulation model which needs upgradation to powerful machines and hardware. With regard to lifecycle simulation, only a few simulation tools seriously consider product lifecycle costs and environmental issues. Furthermore, simulation tools associated with a virtual factory, particularly those concerning data collection, control and monitoring are still in the nascent stage, costly, complex, and difficult to apply.

\section{System Integration}

System integration is the process of connecting various subsystems into one cooperating system to deliver overarching functionality. Modularity in the tasks of running a business via subsystems is often desirable for easier implementation of technological advancements in specific areas, and the ability to adapt quickly to changing needs. However, interoperability, data integration, robustness, stability, and scalability need to be considered for the full benefits of a distributed, modular system to be realised. With the Internet of Things (IoT), another consideration is the capability to handle large volumes of data in real time.

The main means of achieving some form of integration are:

- Point-to-point integration (or one-to-one integration) typically for one function (e.g., many cloud-based applications)

- Vertical integration

- Star integration (or spaghetti integration)

- Horizontal integration often using an Enterprise Service Bus (ESB) or Integration Platform as a Service (iPaaS)

- Common data format integration (e.g., some Enterprise Application Integration (EAI) systems)

Although iPaaS is the leading edge of current systems integration, workflow mediation may be an issue as well as other limiting features such as being tied to a single proprietary platform with a reduced selection of languages, tools, and hosting choices. An exemplar company that uses iPaaS is Taylor Farms, supplying produce to many of the largest supermarket chains and restaurants in the US [22]. Finding the best technological solution depends on the environment in which the system integration method is to be deployed.

The subsystems to be connected may be internal to an organisation, but in food logistics, the environment of connections is both internal and with third parties. A study of logistics integration in the food industry finds that companies should achieve a high level of internal integration before initiating any external integration [23]. A systems integration architecture for a one-stop information management platform for traceability and logistics management of fresh agricultural products supply chain has been proposed [24].

The opportunities presented by system integration include decreased costs and improved efficiency, competitive advantage, and offering better products to customers. These opportunities may be realised by addressing the specific challenges of food logistics within global supply chains of increasing complexity including maintaining quality, safety, and freshness. A highly efficient intelligent logistics system has also the potential to reduce food waste, but efficient algorithms that accommodate uncertainty in demand have 
yet to be developed [25]. Furthermore, considerations such as halal products may require dedicated logistics infrastructure [26].

Recent research indicates that the relationship between information sharing and perishable product supply chains (PPSC) is unclear, indicating the need for additional research [27]. Quality Management Systems (QMSs) are demonstrated to be important in addition to information system integration in European pork supply chains [28]. However, from an efficiency perspective, the challenge lies in harmonising the various QMSs as many are certified and audited separately.

Other challenges to system integration include an unwillingness to share data or outsource certain operations to third parties, unclear communication and responsibilities, functionality disagreements, cost of integration, insufficiently skilled human resources, and lack of standards for integration. Some of these challenges are solvable with iPaaS such as enabling hybrid integration platforms (HIPs) to deal with the integration of legacy systems that may be essential to the core business of an organisation. Existing system integration projects have experienced failure rates of up to $70 \%$. This knowledge alone serves to discourage their implementation. Successful implementation requires appropriate management of the challenges.

\section{Internet of Things (IoT)}

IoT is a network of physical objects (things) which are embedded with sensors and actuators, as well as software that allows the exchange of information with other devices over the Internet [29]. In short, IoT includes everything connected over the Internet, but IoT is being used to define things that communicate with each other.

The complexities involved with global food logistics are already creating challenges with the visibility, transparency, compliance and maintaining of product integrity. In simpler words, long supply chains with multimodal transportation are already adding challenges to real-time monitoring. In the case of a food product recall, a swift and accurate response is needed to avoid any kind of untoward incidents happening due to the consumption of food. The MovingNet is a Vehicular Ad-Hoc Sensor Network comprising of multiple sensors was mounted on a public transport system to detect the production of counterfeit alcohol [30]. Ma et al. [31] demonstrated the incorporation of IoT into the Enterprise Resource Planning (ERP) system of a pork supply chain to create an early warning system in regard to pork quality; the system cut down the logistics costs and improved the circulation efficiency. IoT with increased connectivity can aid in improving the food quality, food safety and operational efficiency by optimising operations through predictive maintenance and reduced operational costs [32-34]. For example, application of IoT in food transportation is shown in Figure 1. The food truck is fitted with various sensors to track vehicle location, monitor temperature, control stock management, and for protection by assessing the vehicle's needs for maintenance, informing about route changes in case of traffic jams, etc.

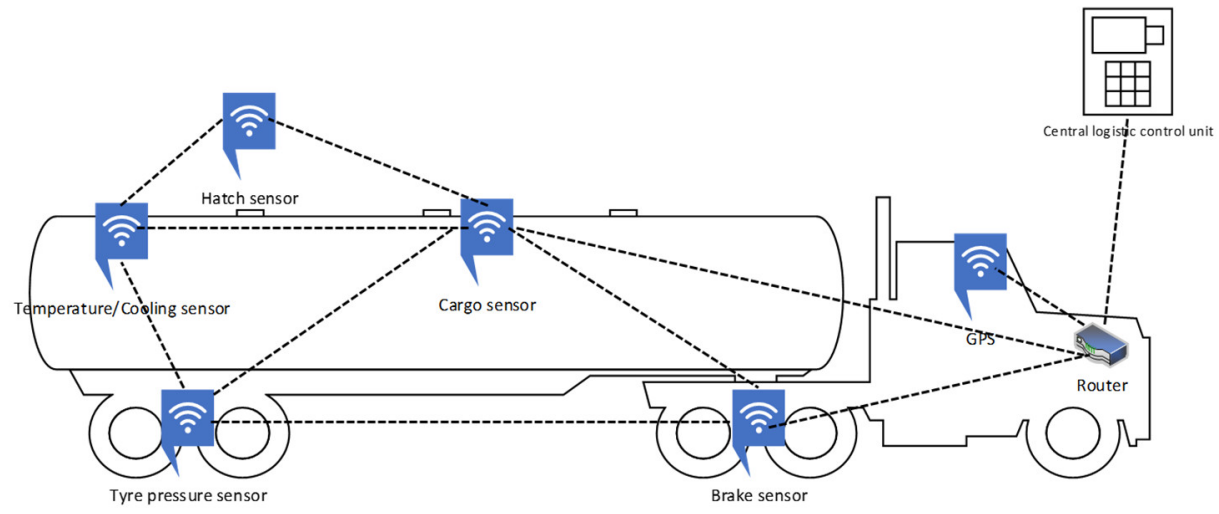

Figure 1. IoT-Powered food haulage truck. 
The other common applications of IoT for food logistics are capacity sensing (communicating about open spaces in a warehouse, port or parking lot), planning and reporting (systems to detect and analyse the delivery network to provide accurate delivery dates and times), route optimisation (to map the shortest or more fuel-efficient route), energy management (to monitor and improve decision-making with regards to the use of fuel and lighting, maintaining required temperature), and fault detection and resolution (monitor faults with transport medium and its maintenance needs). Moreover, it can also be used for environmental monitoring and management (systems that can monitor and control the temperature of the food products), threat detection and prevention (to detect unauthorised openings of food shipments) and real-time traceability (to track not only the shipments but individual food products).

Although IoT has numerous benefits for food logistics systems, it also has its disadvantages. For instance, Ferreira et al. [35] discussed the use of several applications related to vehicular sensing as well as the connectivity issues associated with the mobility and limited wireless range of an infrastructure-less network based only on vehicular nodes. Capturing the data and then analysing it to get meaningful information for the whole food supply chain needs a great deal of infrastructure. As IoT devices are made by different manufacturers and for operability purposes, these devices need to talk to each other but this also raises concerns around data security. The other issue is that a majority of IoT devices are usually shipped with default passwords e.g., 0000, 1111 etc. which makes them easier to be manipulated by unscrupulous agents. Furthermore, developing a new app for every new IoT device and logistics systems is not conducive to scaling.

\section{Cybersecurity}

The information related to data involved in logistics planning and execution is plentiful. The use of technology makes storing and navigating this data easier, which also paves the way for simpler and faster logistics planning. Therefore, gone are the days of paper-tracking, with Industry 4.0, increased digitisation and connectivity, the use of computer-based management systems are increasing widely in supply chains, making them susceptible to cyberattacks [36]. Targeted attacks have been steadily increasing worldwide spanning all industries and sectors, including businesses, schools, hospitals, governmental websites etc. Whenever a new technology is introduced into an industry, cybersecurity becomes an issue. To prepare for technology's adverse consequences, companies must ensure their systems are secure. Cybersecurity is imperative to companies who use computer systems (laptops, tablets, phones, GPS, etc.), wireless internet, Radio Frequency Identification (RFID), any type of sensors, AGV or Artificial Intelligence (AI) [37].

The considerations of cybersecurity within the food industry are scarce; however, with the advancement of Industry 4.0 and the increasing implementation of technologies, it must become a constant thought [38]. The food industry is considered one of the easiest industries to infiltrate due to its unique infrastructure, making bioterrorism a high risk, threatening the welfare of consumers, resources and the economy [37]. The food industry's logistics chain is considered even more vulnerable and prone to cyberattacks due to the large number of stakeholders involved, for example, producers, manufacturers, retailers, etc. [39].

Industry 4.0 is interconnecting companies' physical and virtual systems with the Internet, creating Cyber-Physical Systems (CPS). The use of IoT in this connectivity holds many concerns, as there are still unknowns about upholding security. As these new technologies gather data and control the industry's systems, it puts them under threat of hacking and interference. Guidance on the matter remains scarce as Industry 4.0 unravels. Therefore, Dawson [40] suggests that as companies introduce Industry 4.0 technologies, they should follow several security control regulations to protect them against cyberattacks.

According to Prabhughate [39], the logistics industry has been very slow at adopting technologies that are very promising to its operations. As this continues to increase, the industry can benefit from early detection of the security of their systems, in which 
companies are advised to detect liabilities and ensure a strategic plan is in place for any pitfalls. There are many steps logistics companies can assess in order to reduce the risk of cyberattacks [41]. Before implementing any new technologies into their operations, they can assess its security specifications and consider their risks. Technology providers are able to advise companies on the safety measures needed for certain systems. Conducting staff training to ensure cybersecurity is in place is also efficient for safe operations, phishing email drills are an example of such pieces of training [42]. Along with this, a fallback plan must be in place as there is no guarantee that safety measures taken are enough to prevent security breaches. Lack of cyberattack risk assessment and safety plans make systems vulnerable, further endangering logistics operations.

As the use of more technology and the connectivity of Industry 4.0 continues to be adopted in the food logistics industry, there needs to be greater awareness of the associated cyber threats. The knowledge of planning for and implementing cybersecurity must be widespread; there is also a need for accessible tools to plan for cybersecurity within the food industry as well as policies and regulations [37].

\section{The Cloud}

The cloud is a system used to store data in multiple servers. These servers are typically in a different location than that of the data owner and are managed by a hosting company, who has the responsibility to ensure the data is accessible and safe.

Cloud manufacturing is a concept related to the use of the cloud in manufacturing companies. Cloud manufacturing has been defined as "a model for enabling aggregation of distributed manufacturing resources (e.g., manufacturing software tools, manufacturing equipment, and manufacturing capabilities) and ubiquitous, convenient, on-demand network access to a shared pool of configurable manufacturing services that can be rapidly provisioned and released with minimal management effort or service operator and provider interaction" [43]. Cloud manufacturing provides users with virtualised manufacturing resources, abilities, and capabilities in the form of services over the Internet [44]. The architecture of cloud manufacturing is based on the following layers: resource layer, perception layer, service layer, middleware layer and application layer [45]. Cloud manufacturing can make the manufacturing industry more service-oriented, collaborative, and innovative [46], by sharing manufacturing services, such as computational, software and physical manufacturing resources, offered on-demand [47].

Cloud manufacturing can play a key role in sustainable industries, particularly thanks to collaborative design, greater automation, improved process resilience, and enhanced waste reduction, reuse, and recovery [48]. There are various examples of cloudmanufacturing systems that aid in logistics operations. For instance, [49] integrated cloudmanufacturing and IoT infrastructures to enable a control mechanism for production logistics synchronisation. This system allows real-time data capturing and dynamic resource management. Zhou et al. [50] provided a mathematical model for a logistics scheduling problem with cloud manufacturing, and proposed a scheduling method to reduce the delivery time from manufacturers to customers that performs better than alternative typical strategies.

The cloud can support logistic operations in the food sector. Some of the advantages that the cloud can offer in food logistics are:

- Information can easily be shared and accessed in real time by staff from different departments and even organisations. This improves communication between different agents of the food supply chain and speeds up processes, particularly related to logistics, which rely upon demand from customers to manufacturers.

- Responsibilities for data storage are passed to the hosting company, minimising costs associated with this activity.

- Although using the cloud has a cost, the user only pays for what is being used. Alternatively, if the business stores its own data, it will normally have an excess of capacity in their servers and backup devices, which is not being used. It must also be 
noted that using the cloud usually incurs monthly expenses, while for self-storage of data the costs are typically a one-off.

- Using the cloud allows businesses to cut their energy consumption, reducing energy costs.

- Since data in the cloud is often located in more than one server, usually in different geographical locations, this system also provides a backup function.

- Companies accessing host servers via the cloud can also use different services provided by the host, such as applications. Furthermore, the computer power of the host may be better than that from the company's own devices, enabling businesses to perform some operations faster.

Using the cloud for food logistics also presents some challenges. The main issue is around security concerns. As data is stored in several locations, hackers could try to access it by attacking each location. Using secure systems is paramount to avoid such problems. It is highly recommended to encrypt data before it is stored. Furthermore, private clouds can also be used, instead of or in addition to public clouds.

Storing the data in different locations may also create legal issues, mostly if data is stored in different countries. It is important to make sure there is no breach of regulations.

Another potential problem is that although using the cloud is relatively simple, users must learn the concepts including how to store and access the data in a new way. Additional technology may be needed. This makes the use of cloud systems more complicated. Furthermore, reliance on additional technologies and services may make the system more prone to errors. For instance, a weak or interrupted Internet connection may cause some data stored in the cloud to not be available.

Moreover, although the cloud allows cutting some of the economic costs, as explained above, it must be remembered that implementing these solutions incurs a monetary investment. Most commonly, monthly payments must be arranged. This means that using the cloud may or may not be a more economical solution than more traditional methods. This should be assessed on a case-by-case basis.

In conclusion, the use of the cloud is already widespread in many businesses, including food manufacturing companies with large logistic operations. The cloud presents important advantages over traditional systems, such as simple and quick data sharing. However, disadvantages must also be taken into account, particularly regarding data security. It is also important to assess each case, to elucidate if using the cloud reduces or increases economic costs.

\section{3D Printing}

3D printing, also known as additive manufacturing, has been known for several years, but it is becoming increasingly popular at present. It is an emerging technological innovation capable of transforming and revolutionising plenty of industries, spanning manufacturing, building, education, aviation, and health care including food industry [51,52]. $3 \mathrm{D}$ printing simply refers to processes in which material(s) is/are joined or solidified under computer control to create a $3 \mathrm{D}$ object. The technology is controlled using computer-aided design (CAD) software that instructs a digital fabricating machine to shape 3D objects by successive addition of material layers [53]. Furthermore, 3D printing allows predefined slices of the designed and desired objects to be printed layer by layer (bottom to top) $[53,54]$. Figure 2 shows a generative procedure for 3D printing. Usually, the CAD model produced is made in Standard Tessellation Language (.STL) file format while the model is made as a limited model with triangular facets in the STL document file $[55,56]$. In 3D printing, several techniques exist, using different materials [57]. For example, some of the processes of 3D printing technology include binder jetting [58], directed energy deposition [59], material jetting [60], powder bed fusion/binding [61], sheet lamination [62], vat photopolymerisation [63] and material extrusion [61]. Table 1 shows the description of these processes. 


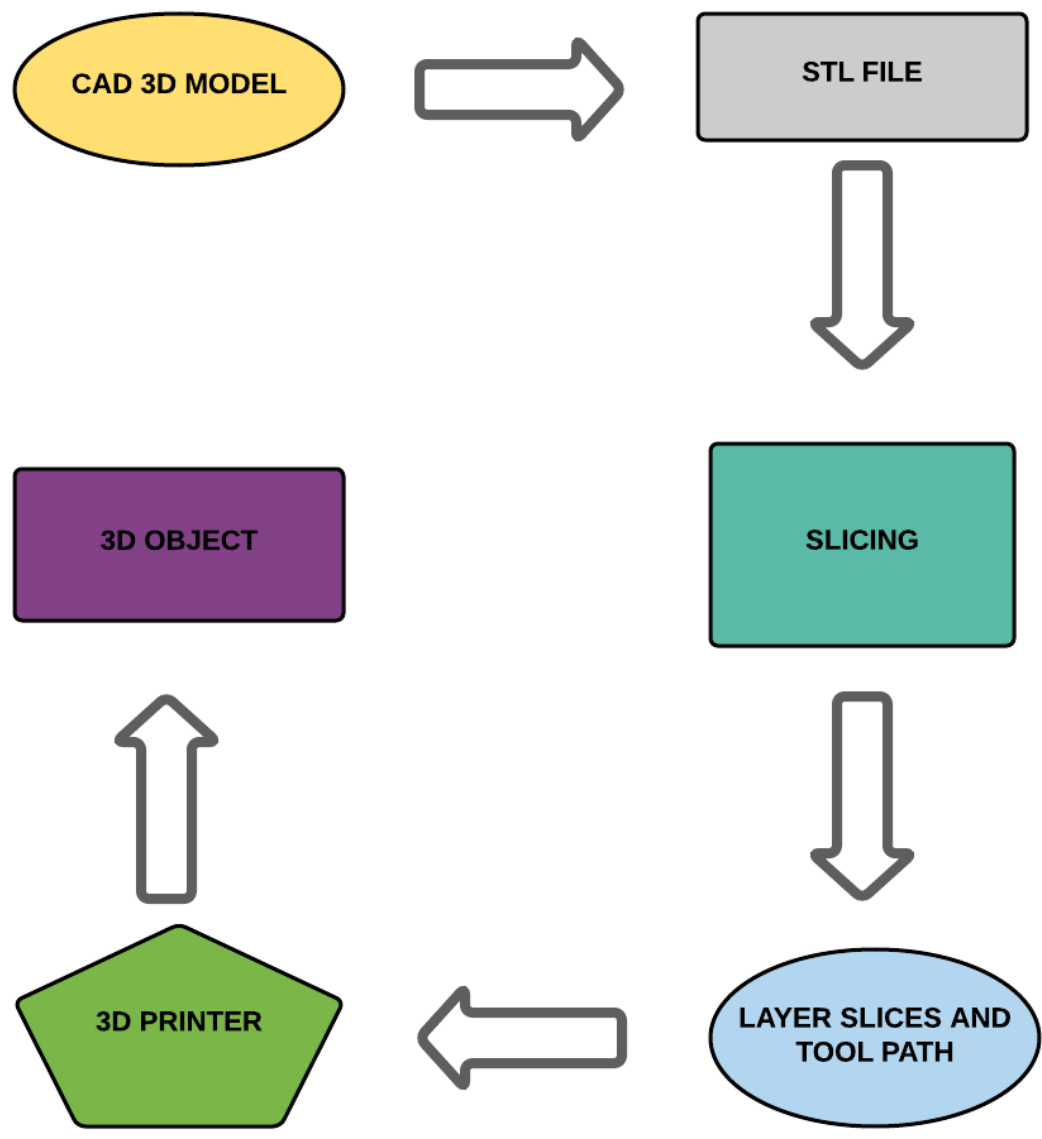

Figure 2. Illustrating the workflow of 3D printing. Adapted from [64].

Table 1. Description of main 3D printing processes.

\begin{tabular}{cc}
\hline Type & Description \\
\hline Binder jetting & $\begin{array}{c}\text { Each powder layer is distributed evenly across the fabrication } \\
\text { platform, and a liquid binder sprays to bind two consecutive } \\
\text { powder layers }\end{array}$ \\
Direct energy deposition & $\begin{array}{c}\text { Energy is directed into a small region to heat a substrate and melt } \\
\text { material being deposited }\end{array}$ \\
The material is pushed out through a nozzle when constant \\
Thessure is applied after which the extruded material will deposit \\
and fully solidify on the substrate at a constant speed \\
Liquid droplets are deposited on the working platform to \\
partially soften the previous layer of material and then solidify as \\
one piece
\end{tabular}

Several potential benefits of 3D printing technology in the food sector have been reported. This technology is emerging as a contemporary method by which food is prepared and presented [65]. Some other potential advantages include customised food designs, personalised and digitalised nutrition, simplifying the supply chain and broadening the source of available food material [66]. Consumers can print different complex food design and customise confectionery shapes with existing data containing culinary knowledge 
and artistic skills from chefs, nutrition experts, and food designers [67]. In practical terms, Foodini, a 3D printer is designed for household kitchens in which food is prepared using a blender and the mix is printed through the 3D printer to create the product [68].

Generally, logistic goals involve achieving the $5 \mathrm{R}$ rule, i.e., delivering the right product at the right place, at the right time, at the right quantity and the right amount [52]. Food logistics are a key part of the food chains that connect producers with consumers, i.e., the food chain is the link between where food is originally produced on the farm, where it is processed, stored, and distributed to consumers. Each stage of the chain will involve logistics which move food, or the products used to produce and protect food in the supply chain [68]. Food logistics is a very complex and arguably an inefficient system, consequently, increasing cost throughout the supply chain, hence, posing real challenges in the adoption of end-to-end, single systems to transport food. 3D printing technology has proven to be efficient in simplifying food supply chain by replacing the traditional processing technology [69], for chocolate printing [70] and for customised food fabrication [71]. The application of this technique will increase the proximity of manufacturing activities to the customers/end-users, thereby reducing transport volume as well as lower packaging, distribution and overriding expenses. As a consequence, managing inventory for food manufacturers would become easier and cheaper as they would be able to manufacture food based on demand. Also, the reduced transportation movement in the supply chains may possibly result in reduced structure wear and tear due to less total traffic from longer distance truck trips. Another advantage of reduced movement is the lowered vehicle emissions which is a bonus to the environment, especially when compared to little or no material wastes from $3 \mathrm{D}$ printing as only the required amount of raw materials is used to make food.

Although the benefits of 3D printing technology have been shown, some challenges for this technology to be widely used in this sector exist. Consumer attitude on 3D food printing and their resultant products is still viewed with suspicion [53]. According to Brunner et al. [72], the acceptance of new food technologies is closely linked to the perceived benefits, risks, and naturalness. The study by Lupton and Turner [73] revealed that most consumers were dissatisfied with food produced by 3D printing technology due to fear that the material is unsafe, inedible, and nutritionally depleted. To increase consumer's interest and appetite, precise and accurate printing must be achieved in cognisance of the material properties, process parameters and post-processing methods [66].

\section{Augmented Reality (AR)}

$\mathrm{AR}$ is a system that connects virtual and real objects by adding digital resources on top of the current view of the real world [74,75]. According to [76], AR systems must combine real and virtual worlds, offer real-time interaction, and provide accurate $3 \mathrm{D}$ registration of virtual and real objects. Hardware needed for AR includes a sensor, to capture the real-time image of the real world, and a screen, where both real and virtual worlds are displayed. Therefore, AR can be used in devices such as tablets, smartphones, eyeglasses, and head-up displays.

The use of AR for industrial applications is named industrial augmented reality (IAR). Although IAR systems are becoming more widespread, this area can be considered a new field, with few industries benefitting from the use of these technologies. To successfully implement AR in an industrial setting, both technology aspects and the organisational fit are key success factors [77].

IAR has already shown important benefits in logistics [78]. For instance, IAR can help to minimise inventory costs by facilitating warehouse management [79]. This can be achieved by reducing the error rate, increasing flexibility, improving reliability, speeding operations, improving the safety of staff, and improving the engagement of operators [80].

Although the use of IAR systems in food logistics has not been explored in detail, it offers a wide range of opportunities in this industrial sector, including in the following areas: 
- Safety of workers. Food industries commonly use heavy machinery for certain operations, e.g., packing and storing in a warehouse. IAR can keep the operator informed about the status of the machinery and highlight any potential risk [81]

- Maintenance. Maintenance of industrial equipment, as well as repair, can be aided by IAR. IAR can show relevant images, videos or highlight specific points of the machinery, as well as give detailed sequential instructions, to support the maintenance of machinery. For instance, Ref. [82] proposed a methodology to create technical documentation in AR based on the use of simplified technical English and 2D symbols.

- $\quad$ Training. As with maintenance, IAR can show images and videos, and give detailed sequential instructions, to train staff in the use of a machine or a specific protocol.

- Quality control. IAR can facilitate the identification of errors, damaged products or products below the quality specifications. For instance, a damaged packaging or missing printed information in a label can be more easily identified with the help of IAR.

- Design and layout. When a new logistics operation is designed and going to be set, IAR can help visualise how the machinery will be placed in the industrial plant or warehouse, and how the flow of materials and machine use will occur. This helps in identifying early errors and optimise logistics operations.

- Communication. IAR can put in touch different members of the team, from the same or different industrial plants. Communication in this case is facilitated by showing the image of the team member in communication with, who can give more clear instructions on how to proceed. Similarly, IAR can facilitate brainstorming and discussion meetings among team members to optimise operations [83].

- Location. IAR can help in identifying where a specific product to be retrieved is located in the warehouse and give directions to staff to find it. Similarly, the areas of the warehouse where free locations are available to store the products can also be identified to speed up logistics operations. IAR can also show where different tools, machinery or areas of the industrial plant are located.

- $\quad$ Language translation. In global food supply chains, food industries receive ingredients from a wide range of countries. Potentially, their labels might be in the local language of origin, which staff may not be able to understand. IAR can provide translations of the product labels by scanning the labels in the original language and providing the automated translation.

- Expiration of products. If expiration dates of each product are stored, IAR can easily identify products that are going to expire shortly and therefore have priority to be sold.

Nevertheless, several challenges are hindering the use of IAR, particularly in food logistics. For instance, privacy issues are one of the major concerns, as a lot of information is often stored in the cloud and could be accessed if the system is hacked. This is why secure systems are particularly important in Industry 4.0. Acceptance of IAR from potential users is also a common problem $[80,84]$ that can be addressed emphasising the advantages of the system and giving adequate training. However, training delivery may be an important disadvantage of IAR, as this costs time and money. In any case, training is necessary to introduce IAR in an industrial setting, as this will be a new technology for most workers, who need to understand how to use it appropriately.

In addition to training costs, the cost of implementing such technology in an industrial setting may be significant, as several devices are required, usually one per worker using IAR. Although these devices are generally expensive, it is expected that their costs will be reduced in the short term, making IAR implementation more economical.

Hardware and software have also been identified as significant limitations of AR that require further research and development. In particular, the user interfaces and user interactions must be improved so AR becomes more widely adopted in the industry $[78,80]$. Improvements in this area are also expected in the near future, as research progresses to optimise IAR systems. 
In conclusion, $\mathrm{AR}$ is already an established technology that can be implemented in systems that support logistics operations, for instance in the food industry. Although there are still some challenges to face, particularly in terms of economic costs and privacy issues, the advantages of such systems are clear. It is expected that AR will be more widely implemented in industrial settings in the near future to optimise industrial operations.

\section{Blockchain}

A large amount of data is being generated by sensors used within the food supply chain. These data can be readily available in real time but need to be accessed in a secure environment. This may be achieved using Blockchain. Blockchain is resistant to any alteration of its data and therefore is being aggressively pursued by industries. In short, it is a distributed and secure ledger which can be retrieved and written from any approved location and its data is stored on a peer-to-peer network rather than in a central location.

Blockchain has several benefits in food logistics such as increased efficiency in shipping, transparency, shipment or goods tracking, fewer issues arising due to misplacement or theft of goods [85] and faster processing of invoicing and payments. It can help to lessen the majority of the issues associated with logistics including procurement, transportation management, track and trace, customs collaboration, and trade finance [86]. Import and export of food products include an excessive amount of paperwork. Maersk found that a single container may need approval from 30 officials including customs, tax, and health authorities [87]. Although containers may take minutes to load but can be held up at the destination port for days if a piece of paper goes missing leading to the spoilage of food. Sometimes the cost of moving and keeping track of all the paperwork equals the cost of physically moving the container around the world. Therefore, Maersk and IBM developed a collaborative Blockchain-based system for digitising trade workflows and end-to-end tracking. This system allows the stakeholders to view the movement and exact location of goods within the supply chain. Additionally, Blockchain technology provides secure data exchange and a tamper-proof repository for this documentation. It has the potential to deliver significant savings through a reduction in delays and fraud. For example, ZIM an ocean shipping company through their pilot project on Blockchain system successfully demonstrated how the bill of lading is issued, transferred, and received through their decentralised network. Blockchain system plays an important role in bringing transparency to the supply chain by collecting and storing the data on how food products are manufactured, where they are sourced from and how they are processed. The information stored on the Blockchain system is permanent and shared seamlessly, giving supply chain partners more complete track and trace competence than before. Hence, this system, in addition to providing legitimacy and authenticity, can also confirm if the product is ethically sourced, its storage conditions and prevent counterfeiting of products. For example, Walmart demonstrated the use of Blockchain technology to track, trace and ensure safety of pork from China and mangoes from Mexico [88]. Blockchain technology can also support with the invoices containing inaccurate data leading to disputes as well as process inefficiencies, which can happen due to misplaced or delayed delivery. Blockchain technology can resolve these disputes by digitising documents and real-time delivery data to generate smart contracts. For example, on delivery of Blockchain connected food products, the time and condition of delivery will be automatically confirmed. Food products can be verified delivered as per the agreed terms and conditions such as temperature, intact packaging, etc. and discharge correct payments to the appropriate partners, thereby increasing efficiency and reliability.

Blockchain technology has numerous benefits; however, it also has its share of challenges such as differing data models among supply chain partners, integration into existing IT system, continuously evolving Blockchain technology and managing the flow of information among supply chain partners [89]. Apart from these challenges, Blockchain also needs to address scalability issues in case of transactions increasing exponentially and limited capacity to handle and store large amounts of data [90]. Wu et al. [90] further claim 
that Blockchain technology has issues associated with data integrity, privacy, and subject to security threats such as mining attack leading to data and revenue loss for food companies. The majority of Blockchain technology projects within the food sector are at a nascent stage and therefore, food manufacturers are still hesitant to pursue this technology aggressively. Also, implementation of Blockchain technology may require significant investments [91] as well as diverse skillsets, knowledge, materials, and expertise to transform digital data into better decision-making [92]. Regulations and policies with regards to the implementation of Blockchain technology in the food sector are not defined by the government and various misconception about the technology need to be addressed as it results in restrictions and limits its adoption in the sector [93].

\section{Artificial Intelligence (AI)}

$\mathrm{AI}$ in industrial applications can be categorised as descriptive, predictive, or prescriptive [94]. Descriptive AI mines the data generated by sensor-enabled operations to uncover new relationships leading to improvements in process design and control. Predictions and prescriptions may be generated by AI if cause-and-effect relationships are at least partially understood. An example of predictive AI is condition-based maintenance which depends on accurate estimates of future failure times. Prescriptive AI generates recommendations for operational actions. The first challenge for research will be to link food logistics needs with appropriate AI.

Decision support systems are not novel, but recent advances in machine learning are being increasingly used in all three categories of AI to move away from model-based algorithms to the use of training data and statistical techniques with only partial or no reliance on models. This expands the range of applications, and there is an opportunity to use this new potential to significantly impact many operations and supply chain processes including the reduction of food waste, control of warehouse conditions and priorities, supplier selection, and shipment delays. Identifying criteria for what comprises appropriate data and the related statistical techniques will be the next challenge.

In food supply chain operations, technologies are mainly used for exchanging information to ensure uninterrupted flow. AI adoption will require the secure sharing of data among all supply chain partners to prepare for future scenarios. However, many small and medium enterprises (SMEs) upstream of food industries are finding it difficult to keep up with the digital transformation [95]. Unclear economic benefits and high investment requirements are barriers to the 4.0 transformation of SMEs [96]. The challenge here will be to enable secure participation of all individual supply chain actors globally. Such a delegation of decisions would allow for rapid adaptation to changing business environments [97].

There are three related initiatives for supply chain strategies: Vendor Managed Inventory (VMI) in which upstream suppliers or manufacturers are authorised to monitor retailers' real-time inventory levels and replenish accordingly; Efficient Consumer Response (ECR) which is applied in the food industry to alleviate supply chain inefficiencies by with retailers share point-of-sales data with supply chain partners; and Collaborative Planning Forecasting and Replenishment (CPFR) which uses real-time data in the supply chain to facilitate demand forecasting, inventory management, production and replenishment planning, and order fulfilment [98]. Due to the price points of food commodities, time-sensitivity, perishability, and shelf-life, CPFR is critical for autonomous decisions across areas such as timely supply, food production, processing, wholesale, distribution, marketing, and retail.

However, there is low adoption of CPFR by upstream actors such as input suppliers, agri-food producers, packaging suppliers, logistics providers, and wholesalers [95]. Retailers face barriers of investment and time required to continually update in-house data management solutions or third-party forecasting systems. In-house systems and various third-party solutions lack standardisation. Resolving standardisation issues will require joint efforts by industry associations, policymakers, and researchers. AI will not truly come 
into its own unless the challenges of low adoption and standardisation are jointly overcome to enable adaptability and self-learning in supply chains.

When sufficient data sharing is realised across the supply chain, the challenge will be to allocate appropriate authority for decision-making. For decentralised decisions, local decision-makers are likely to be favoured due to with access to more immediate information. Leaner logistics planning is likely to be facilitated through decentralised decision-making [97]. However, there is a risk that decentralised decisions may not be in sync with each other and overall objectives. Researchers should investigate the facilitation of decision-making to identify appropriate authority for AI-based logistics platforms.

Humans will still be needed in Food Logistics 4.0, and their work will be influenced and supported by AI. There is a role for human intuition within an IoT and AI application environment in logistics and supply chain processes [99]. Consequently, human factors will have an important impact on the adoption and benefit of AI. Identifying solutions for managing the human-machine interface will be a challenge for researchers.

A related human resource challenge is the lack of qualified employees across the global value chain that have an understanding of data science, information technology, and AI. This is an opportunity for researchers and policymakers to co-create the necessary educational foundations.

\section{Conclusions}

We have discussed various Industry 4.0 technologies and approaches defined under the paradigm of Food Logistics 4.0. We came to the conclusion that technologies and novel solutions such as Robotics and Automation, Big Data, Simulation, System Integration, Internet of Things, Cybersecurity, The Cloud, 3D printing, Augmented Reality, Blockchain, and Artificial Intelligence will be crucial for the sustainable development of food logistics. These technologies will not only improve efficiency but also build customers' trust in the food products they consume. We further identify opportunities available to improve food logistics by adopting Industry 4.0 technologies to reduce cost and time while maintaining the quality of food products during transport within the supply chain. Moreover, the focus on the challenges of these Industry 4.0 technologies indicate possibilities for dealing with them. With this paper, we provide insight to other food supply chain partners into Industry 4.0 technologies which may lead to knowledge transfer and new innovative solutions for a more sustainable food supply chain in which environmental impacts are minimised and socio-economic benefits are maximised.

Author Contributions: Conceptualization, S.J.; Robotics \& automation, F.B.; Big Data, S.J.; Simulation, S.J.; System Integration, H.T.; Internet of things, S.J.; Cybersecurity, F.B.; The Cloud, G.G.-G.; 3D Printing, T.F.; Augmented reality, G.G.-G.; Blockchain, S.J.; Artificial Intelligence, H.T.; Reviewing and editing, K.S. All authors have read and agreed to the published version of the manuscript.

Funding: This research received no external funding.

Institutional Review Board Statement: Not applicable.

Informed Consent Statement: Not applicable.

Data Availability Statement: No new data were created or analyzed in this study. Data sharing is not applicable to this article.

Acknowledgments: We would like to express our sincere gratitude to the editor and anonymous referees for their insightful and constructive comments.

Conflicts of Interest: The authors declare no conflict of interest.

\section{References}

1. Schuh, G.; Rudolf, S.; Riesener, M. Design for Industrie 4.0. In Proceedings of the 14th International Design Conference-DESIGN 2016, Dubrovnik, Croatia, 16-19 May 2016; pp. 1387-1396.

2. Rüßmann, M.; Lorenz, M.; Gerbert, P.; Waldner, M.; Justus, J.; Engel, P.; Harnisch, M. Industry 4.0: The Future of Productivity and Growth in Manufacturing Industries; Boston Consulting Group: Boston, MA, USA, 2015; Volume 9, pp. 54-89. 
3. Fredriksson, A.; Liljestrand, K. Capturing food logistics: A literature review and research agenda. Int. J. Logist. Res. Appl. 2015, 18, 16-34. [CrossRef]

4. RHA. Road Haulage Facts and Stats. Available online: https://www.rha.uk.net/policy-campaigning/top-industry-issues/ haulage-industry (accessed on 14 November 2020).

5. Bader, F.; Rahimifard, S. A methodology for the selection of industrial robots in food handling. Innov. Food Sci. Emerg. Technol. 2020, 64, 102379. [CrossRef]

6. $\quad$ Duong, L.N.K.; Al-Fadhli, M.; Jagtap, S.; Bader, F.; Martindale, W.; Swainson, M.; Paoli, A. A review of robotics and autonomous systems in the food industry: From the supply chains perspective. Trends Food Sci. Technol. 2020, 106, 355-364. [CrossRef]

7. Echelmeyer, W.; Kirchheim, A.; Wellbrock, E. Robotics-logistics: Challenges for automation of logistic processes. In Proceedings of the 2008 IEEE International Conference on Automation and Logistics, Qingdao, China, 1-3 September 2008.

8. Khan, Z.H.; Khalid, A.; Iqbal, J. Towards realizing robotic potential in future intelligent food manufacturing systems. Innov. Food Sci. Emerg. Technol. 2018, 48, 11-24. [CrossRef]

9. Pal, A.; Kant, K. Internet of perishable logistics: Building smart fresh food supply chain networks. IEEE Access 2019, 7, 17675-17695. [CrossRef]

10. Karabegović, I.; Karabegović, E.; Mahmić, M.; Husak, E. The application of service robots for logistics in manufacturing processes. Adv. Prod. Eng. Manag. 2015, 10, 185-194. [CrossRef]

11. Dekhne, A.; Hastings, G.; Murnane, J.; Neuhaus, F. Automation in logistics: Big opportunity, bigger uncertainty. McKinsey Q. 2019, 1-12.

12. Bader, F.; Rahimifard, S. Challenges for industrial robot applications in food manufacturing. In Proceedings of the 2nd International Symposium on Computer Science and Intelligent Control, Stockholm, Sweden, 21-23 September 2018.

13. Gartner. Big Data. Available online: https://www.gartner.com/en/information-technology/glossary/big-data (accessed on 4 November 2020).

14. Syafrudin, M.; Alfian, G.; Fitriyani, N.L.; Rhee, J. Performance analysis of IoT-based sensor, big data processing, and machine learning model for real-time monitoring system in automotive manufacturing. Sensors 2018, 18, 2946. [CrossRef] [PubMed]

15. Jagtap, S.; Duong, L.N.K. Improving the new product development using big data: A case study of a food company. Br. Food J. 2019, 121, 2835-2848. [CrossRef]

16. Pestle Analysis. Using Big Data to Optimize Routing for Trucking-Based Shipping and Logistics. Available online: https:// pestleanalysis.com/using-big-data-to-optimize-routing-for-trucking-based-shipping-and-logistics/ (accessed on 14 November 2020).

17. Liu, S. DHL Uses Big Data to Optimize Last-Mile Delivery. 2017. HBS Digital Initiative. Available online: https:/ /digital.hbs. edu/platform-rctom/submission/dhl-uses-big-data-to-optimize-last-mile-delivery/\# (accessed on 14 November 2020).

18. Ferreira, W.d.P.; Armellini, F.; De Santa-Eulalia, L.A. Simulation in industry 4.0: A state-of-the-art review. Comput. Ind. Eng. 2020, 149, 106868. [CrossRef]

19. Negahban, A.; Smith, J.S. Simulation for manufacturing system design and operation: Literature review and analysis. J. Manuf. Syst. 2014, 33, 241-261. [CrossRef]

20. Tague, M.G. The Power of Digital Twins in Transforming Food Manufacturing. Available online: https://www.foodlogistics. com/technology/article/21128327/the-power-of-digital-twins-in-transforming-food-manufacturing (accessed on 3 November 2020).

21. Hoffa-Dabrowska, P.; Grzybowska, K. Simulation modeling of the sustainable supply chain. Sustainability 2020, $12,6007$. [CrossRef]

22. Redwood Logistics. RedwoodConnect 2.0 Enables Taylor Farms to Get Products "From Field to Fork" Efficiently. Available online: https:/ / www.foodlogistics.com/technology/press-release/21139261/redwood-logistics-redwoodconnect-20-enablestaylor-farms-to-get-products-from-field-to-fork-efficiently (accessed on 12 November 2020).

23. Gimenez, C. Logistics integration processes in the food industry. Int. J. Phys. Distrib. Logist. Manag. 2006, 36, 231-249. [CrossRef]

24. Li, J.; Gao, H.; Liu, Y. Requirement analysis for the one-stop logistics management of fresh agricultural products. J. Phys. Conf. Ser. 2017, 887, 012004. [CrossRef]

25. Li, Y.; Chu, F.; Feng, C.; Chu, C.; Zhou, M. Integrated production inventory routing planning for intelligent food logistics systems. IEEE Trans. Intell. Transp. Syst. 2018, 20, 867-878. [CrossRef]

26. Tieman, M.; Ghazali, M.C. Halal control activities and assurance activities in halal food logistics. Procedia Soc. Behav. Sci. 2014, 121, 44-57. [CrossRef]

27. Lusiantoro, L.; Yates, N.; Mena, C.; Varga, L. A refined framework of information sharing in perishable product supply chains. Int. J. Phys. Distrib. Logist. Manag. 2018, 48, 254-283.

28. Trienekens, J.; Wognum, N. Requirements of supply chain management in differentiating European pork chains. Meat Sci. 2013, 95, 719-726. [CrossRef]

29. Gubbi, J.; Buyya, R.; Marusic, S.; Palaniswami, M. Internet of Things (IoT): A vision, architectural elements, and future directions. Future Gener. Comput. Syst. 2013, 29, 1645-1660. [CrossRef]

30. Ramesh, M.V.; Das, R.N. A public transport system based sensor network for fake alcohol detection. In Proceedings of the International Conference on Wireless Communications and Applications, Sanya, China, 1-3 August 2011. 
31. Ma, C.; Li, Y.; Yin, G.; Ji, J. The monitoring and information management system of pig breeding process based on internet of things. In Proceedings of the 2012 Fifth International Conference on Information and Computing Science, Liverpool, UK, 24-25 July 2012.

32. Bader, F.; Jagtap, S. Internet of things-linked wearable devices for managing food safety in the healthcare sector. In Wearable and Implantable Medical Devices; Academic Press: Cambridge, MA, USA, 2020; pp. 229-253.

33. Jagtap, S.; Rahimifard, S.; Duong, L.N.K. Real-time data collection to improve energy efficiency: A case study of food manufacturer. J. Food Process. Preserv. 2019, e14338. [CrossRef]

34. Jagtap, S.; Rahimifard, S. Unlocking the potential of the Internet of Things to improve resource efficiency in food supply chains. In Proceedings of the International Conference on Information and Communication Technologies in Agriculture, Food \& Environment, Crete, Greece, 21-24 September 2017.

35. Ferreira, M.; Fernandes, R.; Conceiçao, H.; Gomes, P.; d’Orey, P.M.; Moreira-Matias, L.; Gama, J.; Lima, F.; Damas, L. Vehicular sensing: Emergence of a massive urban scanner. In Proceedings of the International Conference on Sensor Systems and Software, Lisbon, Portugal, 4-5 June 2012.

36. Vazirani, A. The Rising Significance of Cybersecurity for Logistics. Available online: https://www.entrepreneur.com/article/35 2836 (accessed on 22 October 2020).

37. Cooper, C. Cybersecurity in food and agriculture. In Protecting Our Future: Educating a Cybersecurity Workforce; Hudson Whitman, Excelsior College Press: Albany, NY, USA, 2015; Volume 2.

38. Culot, G.; Fattori, F.; Podrecca, M.; Sartor, M. Addressing Industry 4.0 cybersecurity challenges. IEEE Eng. Manag. Rev. 2019, 47, 79-86. [CrossRef]

39. Prabhughate, A. Cybersecurity for Transport and Logistics Industry; Infosys: Bengaluru, India, 2020.

40. Dawson, M. Cyber security in industry 4.0: The pitfalls of having hyperconnected systems. J. Strateg. Manag. Stud. 2018, 10, 19-28.

41. Robinson, A. Cybersecurity in the Supply Chain: Challenges and Solutions as the Supply Chain Goes Digital. Available online: https:/ / cerasis.com/cybersecurity-in-the-supply-chain/ (accessed on 11 September 2020).

42. Biologistik, S.A. Cybersecurity Challenges in Logistics and Transport. Available online: https://www.bilogistik.com/en/blog/ cybersecurity-logistics-transport/ (accessed on 11 September 2020).

43. Liu, Y.; Wang, L.; Wang, X.V.; Xu, X.; Jiang, P. Cloud manufacturing: Key issues and future perspectives. Int. J. Comput. Integr. Manuf. 2019, 32, 858-874. [CrossRef]

44. Siderska, J.; Jadaan, K.S. Cloud manufacturing: A service-oriented manufacturing paradigm: A review paper. Eng. Manag. Prod. Serv. 2018, 10, 22-31. [CrossRef]

45. Zhang, L.; Luo, Y.; Tao, F.; Li, B.H.; Ren, R.; Zhang, X.; Guo, H.; Cheng, Y.; Hu, A.; Liu, Y. Cloud manufacturing: A new manufacturing paradigm. Enterp. Inf. Syst. 2014, 8, 167-187. [CrossRef]

46. Ren, L.; Zhang, L.; Wang, L.; Tao, F.; Chai, X. Cloud manufacturing: Key characteristics and applications. Int. J. Comput. Integr. Manuf. 2017, 30, 501-515. [CrossRef]

47. Simeone, A.; Caggiano, A.; Boun, L.; Deng, B. Intelligent cloud manufacturing platform for efficient resource sharing in smart manufacturing networks. Procedia CIRP 2019, 79, 233-238. [CrossRef]

48. Fisher, O.; Watson, N.; Porcu, L.; Bacon, D.; Rigley, M.; Gomes, R.L. Cloud manufacturing as a sustainable process manufacturing route. J. Manuf. Syst. 2018, 47, 53-68. [CrossRef]

49. Qu, T.; Lei, S.P.; Wang, Z.Z.; Nie, D.X.; Chen, X.; Huang, G.Q. IoT-based real-time production logistics synchronization system under smart cloud manufacturing. Int. J. Adv. Manuf. Technol. 2016, 84, 147-164. [CrossRef]

50. Zhou, L.; Zhang, L.; Fang, Y. Logistics service scheduling with manufacturing provider selection in cloud manufacturing. Robot. Comput. Integr. Manuf. 2020, 65, 101914. [CrossRef]

51. Samuel, F.W. 3D printing and supply chain management: A literature review and research agenda. In Proceedings of the 5th International Conference on Mechanical Engineering (Meche), Dubai, UAE, 30 September 2017.

52. Wieczorek, A. Impact of 3D printing on logistics. Res. Logist. Prod. 2017, 7, 443-450. [CrossRef]

53. Jiang, H.; Zheng, L.; Zou, Y.; Tong, Z.; Han, S.; Wang, S. 3D food printing: Main components selection by considering rheological properties. Crit. Rev. Food Sci. Nutr. 2019, 59, 2335-2347. [CrossRef] [PubMed]

54. Ivanova, O.; Williams, C.; Campbell, T. Additive manufacturing (AM) and nanotechnology: Promises and challenges. Rapid Prototyp. J. 2013, 19, 353-364. [CrossRef]

55. Kumar, R.; Kumar, R. 3D printing of food materials: A state of art review and future applications. MaterialsToday Proc. 2020, 33, 1463-1467.

56. Manmadhachary, A.; Kumar, R.; Krishnanand, L. Improve the accuracy, surface smoothing and material adaption in STL file for RP medical models. J. Manuf. Process. 2016, 21, 46-55.

57. Portanguen, S.; Tournayre, P.; Sicard, J.; Astruc, T.; Mirade, P.S. Toward the design of functional foods and biobased products by 3D printing: A review. Trends Food Sci. Technol. 2019, 86, 188-198. [CrossRef]

58. Meteyer, S.; Xu, X.; Perry, N.; Zhao, Y.F. Energy and material flow analysis of binder-jetting additive manufacturing processes. Procedia CIRP 2014, 15, 19-25. [CrossRef]

59. Heigel, J.C.; Michaleris, P.; Reutzel, E.W. Thermo-mechanical model development and validation of directed energy deposition additive manufacturing of Ti-6Al-4V. Addit. Manuf. 2015, 5, 9-19. [CrossRef] 
60. Krujatz, F.; Lode, A.; Seidel, J.; Bley, T.; Gelinsky, M.; Steingroewer, J. Additive Biotech—Chances, challenges, and recent applications of additive manufacturing technologies in biotechnology. New Biotechnol. 2017, 39, 222-231. [CrossRef]

61. Huang, S.H.; Liu, P.; Mokasdar, A.; Hou, L. Additive manufacturing and its societal impact: A literature review. Int. J. Adv. Manuf. Technol. 2013, 67, 1191-1203. [CrossRef]

62. Shimizu, S.; Fujii, H.T.; Sato, Y.S.; Kokawa, H.; Sriraman, M.R.; Babu, S.S. Mechanism of weld formation during very-high-power ultrasonic additive manufacturing of Al alloy 6061. Acta Mater. 2014, 74, 234-243. [CrossRef]

63. Singh, S.; Ramakrishna, S.; Singh, R. Material issues in additive manufacturing: A review. J. Manuf. Process. 2017, 25, 185-200. [CrossRef]

64. Hager, I.; Golonka, A.; Putanowicz, R. 3D printing of buildings and building components as the future of sustainable construction? Procedia Eng. 2016, 151, 292-299. [CrossRef]

65. Raji, I.O. 3D Printing Technology-Applications, Benefits and Areas of Opportunity in Nigeria. Int. J. Adv. Acad. Res.: Sci. Technol. Eng. 2017, 3, 21-30.

66. Liu, Z.; Zhang, M.; Bhandari, B.; Wang, Y. 3D printing: Printing precision and application in food sector. Trends Food Sci. Technol. 2017, 69, 83-94. [CrossRef]

67. Sun, J.; Zhou, W.; Huang, D.; Fuh, J.Y.; Hong, G.S. An overview of 3D printing technologies for food fabrication. Food Bioprocess Technol. 2015, 8, 1605-1615. [CrossRef]

68. Collison, M.; Collison, T.; Myroniuk, I.; Boyko, N.; Pellegrini, G. Transformation Trends in Food Logistics for Short Food Supply Chains-What is New? Stud. Agric. Econ. 2019, 121, 102-110. [CrossRef]

69. Chen, Z. Research on the impact of 3D printing on the international supply chain. Adv. Mater. Sci. Eng. 2016, $2016,4173873$. [CrossRef]

70. Jia, F.; Wang, X.; Mustafee, N.; Hao, L. Investigating the feasibility of supply chain-centric business models in 3D chocolate printing: A simulation study. Technol. Forecast. Soc. Chang. 2016, 102, 202-213. [CrossRef]

71. Sun, J.; Peng, Z.; Zhou, W.; Fuh, J.Y.; Hong, G.S.; Chiu, A. A review on 3D printing for customized food fabrication. Procedia Manuf. 2015, 1, 308-319. [CrossRef]

72. Brunner, T.A.; Delley, M.; Denkel, C. Consumers' attitudes and change of attitude toward 3D-printed food. Food Qual. Prefer. 2018, 68, 389-396. [CrossRef]

73. Lupton, D.; Turner, B. Both fascinating and disturbing: Consumer responses to 3D food printing and implications for food activism. In Digital Food Activism; Schneider, T., Eli, K., Dolan, C., Ulijaszek, S., Eds.; Routledge: London, UK, 2016.

74. Longo, F.; Nicoletti, L.; Padovano, A. Smart operators in industry 4.0: A human-centered approach to enhance operators' capabilities and competencies within the new smart factory context. Comput. Ind. Eng. 2017, 113, 144-159. [CrossRef]

75. Jagtap, S.; Duong, L.; Trollman, H.; Bader, F.; Garcia-Garcia, G.; Skouteris, G.; Li, J.; Pathare, P.; Martindale, W.; Swainson, M.; et al. IoT technologies in the food supply chain. In Food Technology Disruptions, 1st ed.; Galanakis, C., Ed.; Academic Press: Cambridge, MA, USA, 2021.

76. Wu, H.K.; Lee, S.W.Y.; Chang, H.Y.; Liang, J.C. Current status, opportunities and challenges of augmented reality in education. Comput. Educ. 2013, 62, 41-49. [CrossRef]

77. Masood, T.; Egger, J. Augmented reality in support of Industry 4.0-Implementation challenges and success factors. Robot. Comput. Integr. Manuf. 2019, 58, 181-195. [CrossRef]

78. Egger, J.; Masood, T. Augmented reality in support of intelligent manufacturing-A systematic literature review. Comput. Ind. Eng. 2020, 140, 106195. [CrossRef]

79. Mourtzis, D.; Samothrakis, V.; Zogopoulos, V.; Vlachou, E. Warehouse design and operation using augmented reality technology: A papermaking industry case study. Procedia CIRP 2019, 79, 574-579. [CrossRef]

80. Stoltz, M.H.; Giannikas, V.; McFarlane, D.; Strachan, J.; Um, J.; Srinivasan, R. Augmented reality in warehouse operations: Opportunities and barriers. IFAC PapersOnLine 2017, 50, 12979-12984. [CrossRef]

81. Mourtzis, D.; Zogopoulos, V.; Katagis, I.; Lagios, P. Augmented Reality based Visualization of CAM Instructions towards Industry 4.0 paradigm: A CNC Bending Machine case study. Procedia CIRP 2018, 70, 368-373. [CrossRef]

82. Gattullo, M.; Scurati, G.W.; Fiorentino, M.; Uva, A.E.; Ferrise, F.; Bordegoni, M. Towards augmented reality manuals for industry 4.0: A methodology. Robot. Comput. Integr. Manuf. 2019, 56, 276-286. [CrossRef]

83. Benford, S.; Greenhalgh, C.; Reynard, G.; Brown, C.; Koleva, B. Understanding and constructing shared spaces with mixed-reality boundaries. ACM Trans. Comput. Hum. Interact. 1998, 5, 185-223. [CrossRef]

84. Berkemeier, L.; Zobel, B.; Werning, S.; Ickerott, I.; Thomas, O. Engineering of Augmented Reality-Based Information Systems. Bus. Inf. Syst. Eng. 2019, 61, 67-89. [CrossRef]

85. Ship Technology. Cargo Theft: A Billion-Dollar Problem. Available online: https://www.ship-technology.com/features/ featurecargo-theft-a-billion-dollar-problem-5882653/ (accessed on 2 November 2020).

86. DHL. Blockchain in Logistics-Perspectives on the Upcoming Impact of Blockchain Technology and Use Cases for the Logistics Industry. Available online: https://www.dhl.com/content/dam/dhl/global/core/documents/pdf/glo-core-blockchain-trendreport.pdf (accessed on 2 November 2020).

87. Popper, N.; Lohr, S. Blockchain: A Better Way to Track Pork Chops, Bonds, Bad Peanut Butter? Available online: https: //www.nytimes.com/2017/03/04/business/dealbook/blockchain-ibm-bitcoin.html (accessed on 2 November 2020). 
88. Kamath, R. Food traceability on blockchain: Walmart's pork and mango pilots with IBM. J. Br. Blockchain Assoc. 2018, 1, 3712. [CrossRef]

89. Singh, N. Blockchain In Logistics: The Role of Blockchain. 2020. Available online: https:/ /101blockchains.com/blockchain-inlogistics / (accessed on 2 November 2020).

90. Wu, M.; Wang, K.; Cai, X.; Guo, S.; Guo, M.; Rong, C. A comprehensive survey of blockchain: From theory to IoT applications and beyond. IEEE Internet Things J. 2019, 6, 8114-8154. [CrossRef]

91. Hughes, L.; Dwivedi, Y.K.; Misra, S.K.; Rana, N.P.; Raghavan, V.; Akella, V. Blockchain research, practice and policy: Applications, benefits, limitations, emerging research themes and research agenda. Int. J. Inf. Manag. 2019, 49, 114-129. [CrossRef]

92. Klerkx, L.; Jakku, E.; Labarthe, P. A review of social science on digital agriculture, smart farming and agriculture 4.0: New contributions and a future research agenda. NJAS Wagening. J. Life Sci. 2019, 90, 100315. [CrossRef]

93. Lin, Q.; Wang, H.; Pei, X.; Wang, J. Food safety traceability system based on blockchain and EPCIS. IEEE Access 2019, 7, 20698-20707. [CrossRef]

94. Olsen, T.L.; Tomlin, B. Industry 4.0: Opportunities and challenges for operations management. Manuf. Serv. Oper. Manag. 2020, 22, 113-122. [CrossRef]

95. Soosay, C.; Kannusamy, R. Scope for industry 4.0 in agri-food supply chain. In Proceedings of the Hamburg International Conference of Logistics (HICL), Berlin, Germany, 12-14 September 2018; Volume XXV, pp. 37-56.

96. Trollman, H.; Trollman, F. A sustainability assessment of smart innovations for mass production, mass customisation and direct digital manufacturing. In Mass Production Processes; IntechOpen: Rijeka, Croatia, 2019.

97. Schuh, G.; Anderl, R.; Gausemeier, J.; ten Hompel, M.; Wahlster, W. Industrie 4.0 Maturity Index. Managing the Digital Transformation of Companies; Herbert Utz: Munich, Germany, 2017.

98. Hill, C.A.; Zhang, G.P.; Miller, K.E. Collaborative planning, forecasting, and replenishment \& firm performance: An empirical evaluation. Int. J. Prod. Econ. 2018, 196, 12-23.

99. Klumpp, M.H.M.; Meyer, O.; Ruiner, C.; Gruhn, V. Production logistics and human-computer interaction-State-of-the-art, challenges and requirements for the future. Int. J. Adv. Manuf. Technol. 2019, 105, 3691-3701. [CrossRef] 